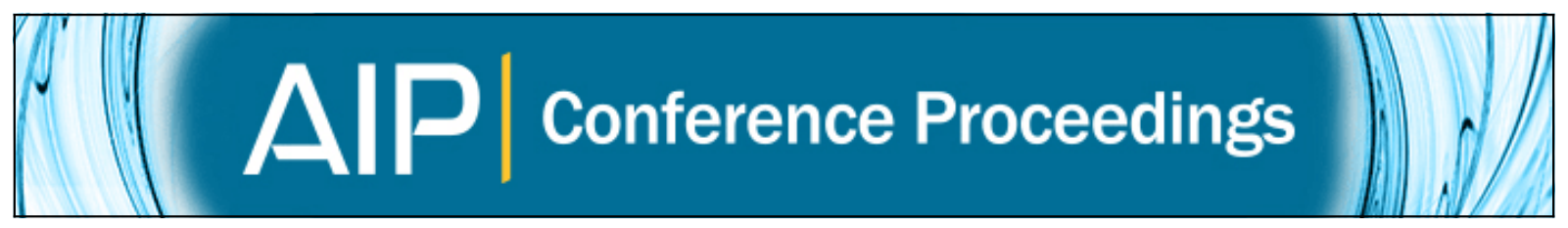

\title{
Three-dimensional Ion Distribution in a Filtered Vacuum Arc Discharge
}

H. Kelly, A. Marquez, and M. Pirrera

Citation: AIP Conference Proceedings 875, 254 (2006); doi: 10.1063/1.2405943

View online: http://dx.doi.org/10.1063/1.2405943

View Table of Contents: http://scitation.aip.org/content/aip/proceeding/aipcp/875?ver=pdfcov

Published by the AIP Publishing

\section{Articles you may be interested in}

Experimentally established correlation between ion charge state distributions and kinetic ion energy distributions in a direct current vacuum arc discharge

J. Appl. Phys. 117, 093301 (2015); 10.1063/1.4914301

Three-dimensional model and simulation of vacuum arcs under axial magnetic fields

Phys. Plasmas 19, 013507 (2012); 10.1063/1.3677881

Study of Linear Magnetic Filters in a Pulsed Copper Vacuum Arc

AIP Conf. Proc. 875, 199 (2006); 10.1063/1.2405930

Influence of gas pressure and cathode composition on ion energy distributions in filtered cathodic vacuum arcs J. Appl. Phys. 83, 2965 (1998); 10.1063/1.367052

Influence of reactive gas on ion energy distributions in filtered cathodic vacuum arcs Appl. Phys. Lett. 71, 1777 (1997); 10.1063/1.119428 


\title{
Three-dimensional Ion Distribution in a Filtered Vacuum Arc Discharge
}

\author{
H. Kelly ${ }^{*}$, A. Marquez ${ }^{*}$ and M. Pirrera ${ }^{\#}$ \\ Instituto de Física del Plasma, CONICET-Dpto. de Física, FCEN, UBA \\ Ciudad Universitaria Pab. 1, (1428EHA) Ciudad de Buenos Aires
}

\begin{abstract}
Three-dimensional measurements of the ion flux along the filter of a magnetically filtered d-c vacuum arc are presented. The device includes a metallic plasma-generating chamber with cooper electrodes coupled to a substrate chamber through a quarter-torus magnetic filter. The filtering magnetic field was high enough to magnetize the electrons but not the ions. The ion current distribution was studied using a multi-element $\mathrm{Cu}$ probes, placed at three different positions along the filter. The ion saturation current of each probe was measured by biasing the probe at $-70 \mathrm{~V}$ with respect the grounded anode. Preliminary results of the three dimensional ion flux distribution and the floating potential of the plasma as functions of the bias filter voltage and magnetic field intensity are reported.
\end{abstract}

Keywords: Vacuum arc discharge, magnetic filter, ion saturation current.

PACS: $52,52.80 . \mathrm{Vp}, 52.77 .-\mathrm{j}$

\section{INTRODUCTION}

The cathodic vacuum arc is widely used to produce coatings [1]. The deposited material comes from highly ionized plasma ejected from cathode spots. The kinetic energies of the ions are in the range $15-120 \mathrm{eV}$, depending on the cathode material and on the charge-state of the ion [2], and with a total ion current amounting to $8-10 \%$ of the total discharge current [3]. The presence of microdroplets of melted cathode material in the coatings is a disadvantage in vacuum arc technology, since for some applications this macroparticles increase the porosity and roughness of the coating. The most popular system used to separate the metallic plasma from the microdroplets, are based on a focusing magnetic field that magnetize the electrons and guide the metallic plasma through the filter to the substrate but leave unchanged the microdroplet flux [4]. However, part of the plasma flux is lost in the filter; so many efforts have been devoted to the optimization of filters (by applying a positive bias voltage of about $10-20 \mathrm{~V}$ to the filter with respect to the plasma potential). Straight [5] and curved [6] filters have been studied. Presently, the one most often employed in practice is the so-called "quarter torus filter" (developed by Aksenov). It consists in a circular non-magnetic metallic tube with a bending angle of $90^{\circ}$, and with a toroidal magnetic field generated by an external coil. The magnetic field intensity is in the range $50-500 \mathrm{G}$, a value enough high to magnetize the plasma electrons.

In a previous work, the magnetic filter was characterized along its axis, by using only a single probe [7]. In this work we present preliminary results of a three dimensional study of the ion distribution and the plasma floating potential, measured as functions of the bias filter potential and magnetic field intensity performed with a magnetically filtered .

\section{EXPERIMENTAL SETUP}

The investigations were carried out in a d-c filtered vacuum arc system, which is shown schematically in Fig.1 (DCF2 device at INFIP). There is a plasma generation chamber that includes a water-cooled copper cylindrical cathode $(60 \mathrm{~mm}$ in diameter) surrounded by a floating shield, an annular watercooler cooper anode ( $80 \mathrm{~mm}$ in diameter), and a tungsten striker which is brought into contact with the cathode surface and later removed to trigger the discharge. The anode was grounded. At the exit of this chamber is connected a magnetic quarter torus filter (500 mm length, $100 \mathrm{~mm}$ inner diameter) made of corrugated stainless steel, including an external coil that produces the filtering magnetic field. The bending angle of the torus is $90^{\circ}$. At the exit of the torus a deposition stainless steel vacuum chamber (cross shaped) is connected. The plasma generation chamber, magnetic filter and deposition chamber are

\footnotetext{
* Member of the CONICET

${ }^{\#}$ Fellow of the CONICET
} 
electrically isolated among them. By employing an independent $\mathrm{d}$-c power source, the magnetic filter can be biased with respect to the plasma at a positive $\mathrm{V}_{\mathrm{BF}}$ potential. Two vacuum systems (composed of mechanical and diffusion pumps) pump separately the plasma generation and deposition chambers to a base pressure of less than $10^{-4} \mathrm{mbar}$. The arc was operated in a continuous mode with an arc current of $100 \mathrm{~A}$.

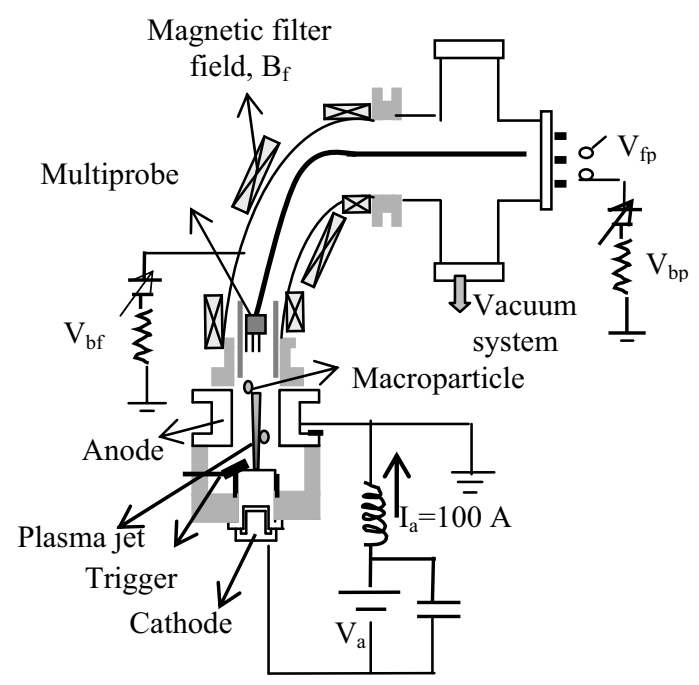

FIGURE 1. Scheme of the DCF2 device.

The magnetic field generating coil was fed by an independent $\mathrm{d}$-c variable current source, so that the filter magnetic field $\mathrm{B}_{\mathrm{F}}$ values (measured by a Hall probe) varied in the range $0-110 \mathrm{G}$. The maximum field corresponded to a coil current of $70 \mathrm{~A}$, and was obtained at the knee of the torus.

The ion current distribution was studied using a multi-element probe, placed at three different positions along the filter, (at the entrance (A), in the middle knee (B) and at the exit (C)). Three individual spherical $\mathrm{Cu}$ probes $(2 \mathrm{~mm}$ diameter), electrically insulated among them, were located on a PVC probe holder. The three dimensional measurements were done by rotating the holder and moving it along the filter.

In the Fig.2 a scheme of the probe sensed positions on a transversal section of the filter are indicated. It should be noted that at position B the lower points (6-7, 14-17) could not be sensed because of geometrical limitations of the multiprobe diagnostic.

The ion saturation current $\mathrm{I}_{\mathrm{ION}}$ of each probe was measured by biasing the probes at $-70 \mathrm{~V}$ with respect the grounded anode and its values were registered by measuring the induced voltage drop on a resistor connected in series with the biasing power source.

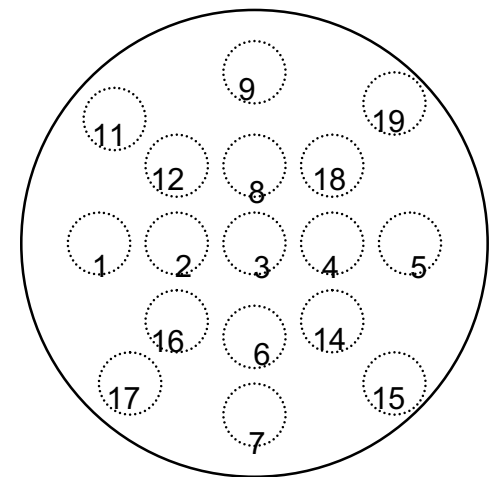

FIGURE 2. Probe positions into the filter

A high-impedance resistive voltage divider was also employed to register the floating potential of the probes, $\mathrm{V}_{\mathrm{FP}}$, and filter floating potential $\mathrm{V}_{\mathrm{FF}}$. The electrical signals were registered in a four channel digitizing oscilloscope (sampling rate of $1 \mathrm{GS} / \mathrm{s}$, analogical bandwidth of $100 \mathrm{MHz}$ ).

\section{RESULTS}

\section{Saturation Ion Current}

In the Fig. $3 \mathrm{I}_{\mathrm{ION}}$ vs. $\mathrm{B}_{\mathrm{F}}$ with floating filter potential for positions A3, A7 and A9 (entrance) is presented. Within experimental uncertainties it can be seen that $\mathrm{I}_{\mathrm{ION}}$ is almost independent of the position and this result was found also for the other position investigated (not shown for clarity). Also it was found that $\mathrm{I}_{\mathrm{ION}}$ was independent of $\mathrm{B}_{\mathrm{F}}$. $\left(\mathrm{I}_{\mathrm{ION}} \sim 2.5\right.$ $\mathrm{mA}$ )

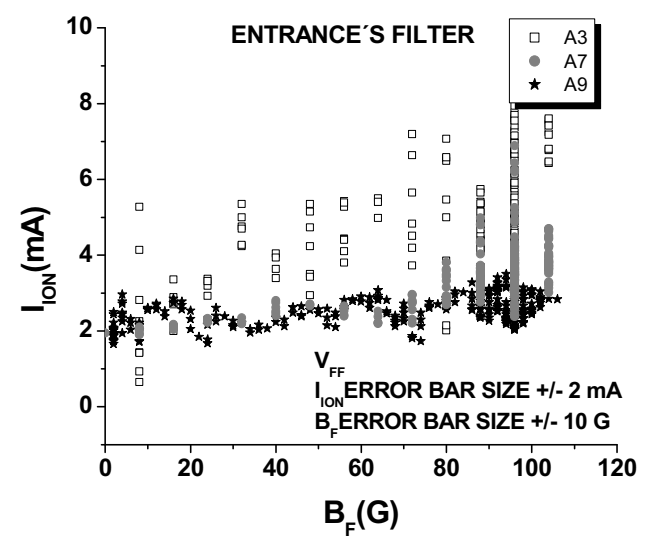

FIGURE 3. $\mathrm{I}_{\mathrm{ION}} \mathrm{vs} \mathrm{V}_{\mathrm{B}}$ at the entrance's filter, at probe positions 3, 7, and 9; with $\mathrm{V}_{\mathrm{FF}}$.

In the Fig. $4 \mathrm{I}_{\mathrm{ION}}$ vs. $\mathrm{B}_{\mathrm{F}}$ with floating filter potential for positions B3, B8 and B9 (knee) is presented. It can be seen that now $\mathrm{I}_{\mathrm{ION}}$ depends on 
the position (being smaller at the upper position, where $\mathrm{B}_{\mathrm{F}}$ is smaller) and also increases with $\mathrm{B}_{\mathrm{F}}$. Typically, the current collected at the upper positions increased from $0.18 \pm 0.02 \mathrm{~mA}\left(\mathrm{~B}_{\mathrm{F}} \cong 0\right)$ to $1.2 \pm 0.2$ $\mathrm{mA}\left(\mathrm{B}_{\mathrm{F}} \cong 110 \mathrm{G}\right)$.

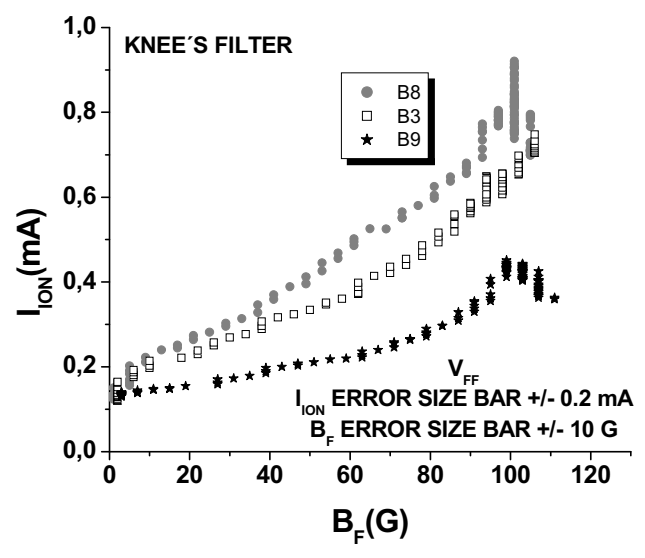

FIGURE 4. $\mathrm{I}_{\mathrm{ION}}$ vs $\mathrm{V}_{\mathrm{B}}$ at the filter's knee, in probe positions 3,7 , and 9 ; with $\mathrm{V}_{\mathrm{FF}}$.

In Fig. $5 \mathrm{I}_{\mathrm{ION}}$ vs. $\mathrm{B}_{\mathrm{F}}$ with the filter floating for positions $\mathrm{C} 3, \mathrm{C} 7$ and $\mathrm{C} 9$ (exit) is presented. $\mathrm{I}_{\mathrm{ION}}$ is larger at the upper position $\mathrm{C} 9$ and smaller at the lower position $\mathrm{C} 7$ and as shown in Fig.4 there is also a marked dependence on $\mathrm{B}_{\mathrm{F}}$. For a given value of $\mathrm{B}_{\mathrm{F}}$ the probes located at the upper positions 1-5, 8-11 and 16-17, registered always a larger current than those located the lower positions 6-7 and 12-15.

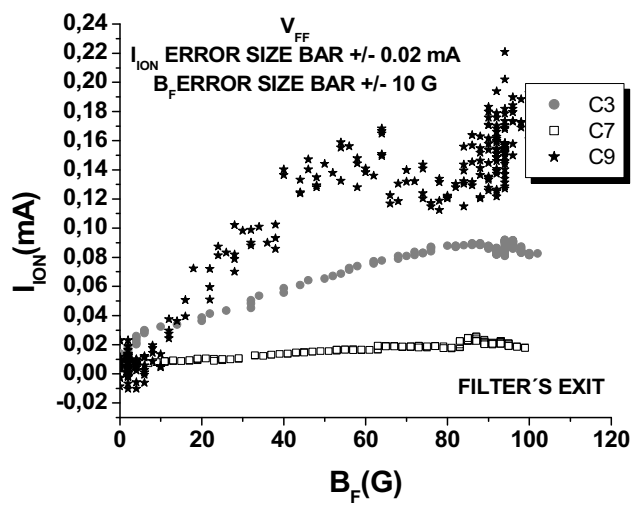

FIGURE 5. $\mathrm{I}_{\mathrm{ION}}$ vs $\mathrm{V}_{\mathrm{B}}$ at the exit of the filter, at probe positions 3, 7, and 9; with $\mathrm{V}_{\mathrm{FF}}$.

Typically, the current collected at the lower positions increased from $0.02 \pm 0.02 \mathrm{~mA}\left(\mathrm{~B}_{\mathrm{F}} \simeq 0 \mathrm{G}\right)$ to $0.18 \pm 0.02 \mathrm{~mA}\left(\mathrm{~B}_{\mathrm{F}} \simeq 110 \mathrm{G}\right)$.

By comparing Fig. 3 to 5 , the ion loses in the filter are apparent. The efficiency of the filter, $\mathrm{I}_{\mathrm{ION}}$ (C)/ $\mathrm{I}_{\mathrm{ION}}(\mathrm{A})$, increases with $\mathrm{B}_{\mathrm{F}}$ from $0.8 \%$ to $7 \%$ for a floating filter.
In Fig. $6 \mathrm{I}_{\mathrm{ION}}$ as a function of $\mathrm{V}_{\mathrm{BF}}$, for the maximum intensity of $\mathrm{B}_{\mathrm{F}}\left(\mathrm{B}_{\mathrm{FMAX}}\right)$ at the knee of the QT filter, is shown for the positions B3, B8 and B9. $\mathrm{I}_{\mathrm{ION}}$ is higher at the central position $\mathrm{B} 3$ and the beginning increases with $\mathrm{V}_{\mathrm{BF}}$ reaching a broad maximum for $\mathrm{V}_{\mathrm{BF}} \sim 15 \mathrm{~V}$. In this case $\mathrm{I}_{\mathrm{ON}}$ increases from $0.4 \pm 0.2 \mathrm{~mA}\left(\mathrm{~V}_{\mathrm{BF}} \simeq 0 \mathrm{~V}\right)$ to $2.2 \pm 0.2 \mathrm{~mA}$ $\left(\mathrm{V}_{\mathrm{BF}} \cong 15 \mathrm{~V}\right)$. Also $\mathrm{I}_{\mathrm{ION}}$ strongly decreases in the radial direction and there is no a defined behavior with $\mathrm{V}_{\mathrm{BF}}$ for the other positions shown in the figure.

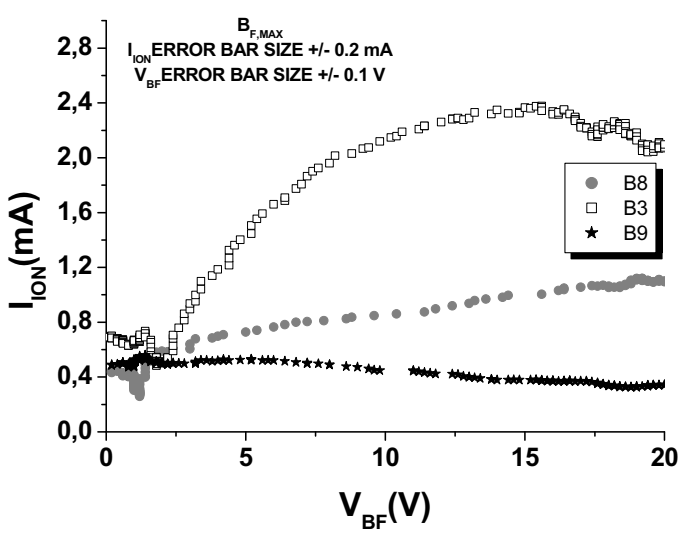

FIGURE 6. $\mathrm{I}_{\mathrm{ION}} \mathrm{vs} \mathrm{V}_{\mathrm{BF}}$ at the knee of the filter, at probe positions 3, 7, and 9; with $\mathrm{B}_{\mathrm{MAX}}$.

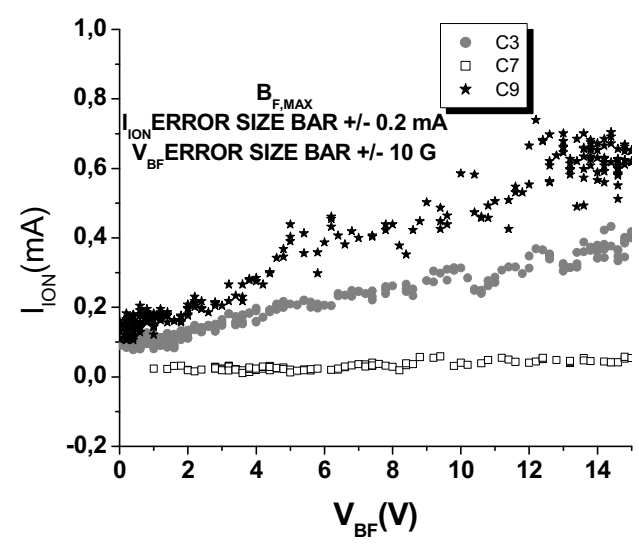

FIGURE 7. $\mathrm{I}_{\mathrm{ION}}$ vs $\mathrm{V}_{\mathrm{BF}}$ at the exit of the filter, at probe positions 3, 7, and 9; with $\mathrm{B}_{\mathrm{MAX}}$.

In Fig.7 $\mathrm{I}_{\mathrm{ION}}$ as a function of $\mathrm{V}_{\mathrm{BF}}$, for $\mathrm{B}_{\mathrm{FMAX}}$ at the exit of the QT filter, is shown for the positions C3, C7 and C9. In can be seen a similar behavior of $\mathrm{I}_{\mathrm{ION}}$ as that shown in Fig. 5 (that is the ion flux concentrated at the upper positions of the filter), but with absolute values increased due to the bias effect. For example, $\mathrm{I}_{\mathrm{ION}}$ increases at the upper probe 
positions from $0.2 \pm 0.2 \mathrm{~mA}\left(\mathrm{~V}_{\mathrm{BF}} \simeq 0 \mathrm{~V}\right)$ to $0.8 \pm 0.2$ $\mathrm{mA}\left(\mathrm{V}_{\mathrm{BF}} \cong 20 \mathrm{~V}\right)$.

By comparing the intensity of $\mathrm{I}_{\mathrm{ION}}$, the ion loses in the filter are again, apparent: the efficiency of the filter, $\mathrm{I}_{\mathrm{ION}}(\mathrm{C}) / \mathrm{I}_{\mathrm{ION}}(\mathrm{A})$, increases with $\mathrm{V}_{\mathrm{BF}}$ from $7 \%$ to $14 \%$ for $\mathrm{B}_{\mathrm{FMAX}}$.

\section{Floating Potentials}

In Fig. $8 \mathrm{~V}_{\mathrm{FF}}$ vs $\mathrm{B}_{\mathrm{F}}$ is presented. It can be seen that $V_{F F}$ is negative for $B_{F} \leq 90 \mathrm{G}$ while it becomes positive for higher values of $B_{F}$ indicating magnetization of electrons.

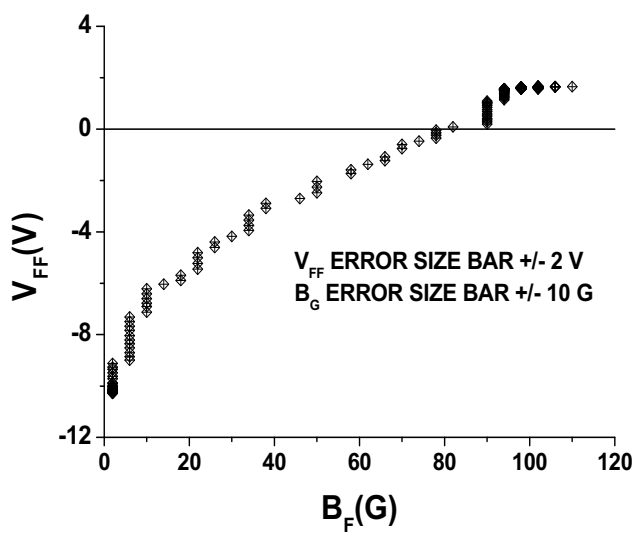

FIGURE 8. $\mathrm{V}_{\mathrm{FF}}$ Vs $\mathrm{B}_{\mathrm{F}}$

The dependence of the $V_{F P}$ with the filter magnetic field $\mathrm{B}_{\mathrm{F}}$ was studied along the filter, using the probes showed in Fig. 2. For $\mathrm{B}_{\mathrm{F}}=0 \mathrm{G}$ and nonbiased filter, $\mathrm{V}_{\mathrm{FP}}$ decreased along the filter from $-6 \pm$ 4 Vat position $\mathrm{A}$ to $-14 \pm 4 \mathrm{~V}$ at position $\mathrm{B}$ and $\mathrm{C}$, but the local value of $\mathrm{V}_{\mathrm{FP}}$ increases at the outer points influenced by the filter potential at position $\mathrm{C}$. The higher values at the entrance seems to be influenced by the anode potential $\left(\mathrm{V}_{\text {anode }} \sim 0 \mathrm{~V}\right)$ and in a weakly way by $\mathrm{V}_{\mathrm{FF}}=-10 \pm 2 \mathrm{~V}$.

For $\mathrm{B}_{\mathrm{FMAX}}\left(\mathrm{V}_{\mathrm{FF}}=1 \pm 1 \mathrm{~V}\right), \mathrm{V}_{\mathrm{FP}}$ takes higher values with respect to the previous situation, reaching $-8 \pm 4$ Vat the entrance, to $-12 \pm 4 \mathrm{~V}$ at the QT exit.

On the other hand, when the QT filter is biased, there is no considerably change in the $\mathrm{V}_{\mathrm{FP}}$ values at position $\mathrm{A}\left(\mathrm{V}_{\mathrm{FP}}=-8 \pm 4 \mathrm{~V}\right)$ for different values of $\mathrm{V}_{\mathrm{BF}}$. At position $\mathrm{B}$ and $\mathrm{C}$ also no significantly changes in $\mathrm{V}_{\mathrm{FP}}$ with $\mathrm{V}_{\mathrm{BF}}$ were found. The only point to note is that at the filter exit, the $\mathrm{V}_{\mathrm{FP}}$ values at the upper position of the filter $\left(\mathrm{V}_{\mathrm{FP}}=-10 \pm 4 \mathrm{~V}\right)$ were somewhat higher that those found at the lower position $\left(\mathrm{V}_{\mathrm{FP}}=-4 \pm 4 \mathrm{~V}\right)$.

\section{CONCLUSIONS}

The measurements of $\mathrm{I}_{\mathrm{ION}}$ indicate that there is an electron confinement due to $\mathrm{B}_{\mathrm{F}}$, and the filter efficiency increase with its value. The biasing of the filter improves the efficiency of the system, reaching $14 \%$ for the optimized parameters of DCF2.

The obtained data for the ion current and plasma floating potential will be coupled in the near future to a hydrodynamic model for the filter.

\section{ACKNOWLEDGEMENTS}

This work was supported by grants from the Agencia Nacional de Promoción Científica y Tecnológica (PICT 03-09491), Universidad de Buenos Aires (PID X111, PID X146), and CONICET (PIP 02239, PEI 6011)

\section{REFERENCES}

1. R. L. Boxman, D. M. Sanders and P. J. Martin; Handbook of Vacuum Arc Science and Technology, Fundamentals and Applications, Park Rige, NJ: Noyes, 1995.

2. G. Y. Yushkov, A. Anders, E. M. Oks and I. G. Brown; J. Appl. Phys. 88, 5618 (2000).

3. C. W. Kimbling; J. Appl. Phys. 44, 3074 (1973).

4. I. I. Aksenov, V. A. Belous, V. G. Padalka and V. M. Khoroshikh; Sov. J. Plasma Phys. 4, 425 (1978).

5. H. Kelly, L. Giuliani and F. Rausch; J. Phys. D: Appl. Phys. 36, 1980 (2003).

6. R. L. Boxman, V. N. Zhitomirsky, B. Alterkop, E. Gidalevich, M. Keidar and S. Goldsmith; Surf. Coat. Technol. 86-87, 243 (1996).

7. H. Kelly, A. Marquez, M. Pirrera, Brazilian Journal of Physics, Vol. 34 - no 4B - December 2004 